\title{
Current Status in Diagnosis and Treatment of Hereditary Thrombotic Thrombocytopenic Purpura
}

\author{
Hayley A Hanby ${ }^{2}$ and X. Long Zheng ${ }^{1,2^{*}}$ \\ ${ }_{1}^{1}$ Deparment of Cell and Molecular Biology Graduate Group, The University of Pennsylvania Perelman School of Medicine Philadelphia, PA, USA \\ 2 Department of Pathology and Laboratory Medicine, The Children's Hospital of Philadelphia, PA, USA
}

*Corresponding author: X. Long Zheng, The University of Pennsylvania Perelman School of Medicine, Philadelphia, USA, PA 19104, Tel: 215-590-3565; Fax: 267-426-5165;E-mail:zheng@email.chop.edu

Rec date: April 09, 2014, Acc date: April 09, 2014, Pub date: April 11, 2014

Copyright: ( 2014 Hanby HA, et al. This is an open-access article distributed under the terms of the Creative Commons Attribution License, which permits unrestricted use, distribution, and reproduction in any medium, provided the original author and source are credited.

\section{Editorial}

Thrombotic Thrombocytopenic Purpura (TTP) is an acute and potentially fatal hematologic disorder. It is characterized by systemic platelet clumping in the microvasculature and small arterioles, resulting in thrombocytopenia and microangiopathic hemolytic anemia [1]. Some patients may present signs and symptoms that are consistent with end organ dysfunction [2]. The pathology of this disorder derives from the deficiency of plasma metalloenzyme ADAMTS13 (A Disintegrin and Metalloprotease with Thrombo Spondin type-1 repeats, 13) [3,4]. Under physiological conditions, ADAMTS13 cleaves ultra-large VWF (UL-VWF) that is released from endothelial cells upon activation or vascular injury [5-7]. This proteolytic cleavage of UL-VWF by ADAMTS13 in plasma is essential to remove UL-VWF from endothelial surface and to subsequently reduce the size of VWF multimers in circulation (Figure 1).

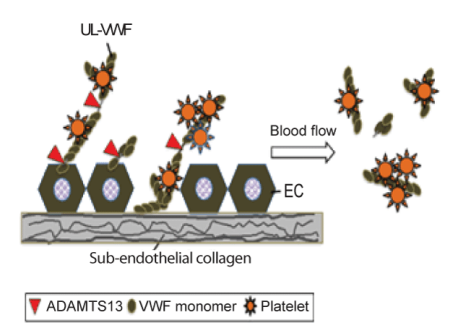

Figure 1: The role of ADAMTS13 in normal hemostasis.

TTP can be divided into at least two major forms: hereditary TTP, also known as Upshaw-Schulman syndrome (USS), is rare, accounting for $2-4 \%$ of all TTP cases $[4,8,9]$; acquired TTP, primarily caused by autoantibody-mediated inhibition of plasma ADAMTS13 activity [10-13], occurs more in adults, particularly in African American women. Interestingly, the manifestation of hereditary TTP is usually seen after an acute illness such as infection or during pregnancy $[14,15]$. Intermittent plasma infusion is often sufficient for treatment of hereditary TTP [16]. However, plasma exchange is often required for the treatment of acquired autoantibody-associated TTP [2,12,17], which replenishes the deficient plasma ADAMTS13 protease and removes immunoglobulin G-type autoantibodies against ADAMTS13.

Hereditary TTP is primarily seen in neonates and children $[8,14,18]$, but it can occur in adults [8]. A presumptive diagnosis of hereditary TTP can be made if a patient presents with thrombocytopenia and microangiopathic hemolytic anemia (i.e. low hematocrit, low or absence of serum hepatoglobin, elevated serum lactate dehydrogenase, and fragmentation of red blood cells) with or without organ dysfunctions including central nerve system, cardiac, and renal. If available, plasma ADAMTS13 activity and inhibitor tests are important for the differentiation of TTP from a similar syndrome, atypical hemolytic uremic syndrome (aHUS) [19]. Unlike classic HUS that is commonly caused by toxin-producing E. coli, aHUS is found to be associated with abnormalities in one or several complement components such as complement C3 [20] and factor B [21,22] or complement regulatory proteins including factor $\mathrm{H}$, factor $\mathrm{I}$, and membrane cofactor protein [23]. When plasma ADAMTS13 activity is less than 5\% with no detectable anti-ADAMTS13 antibodies, a diagnosis of hereditary TTP should be considered. Normal to moderately reduced plasma ADAMTS13 activity does not completely rule out TTP. In this case, plasma infusion or exchange should still be tried initially and a complete blood count should be performed daily to monitor the response to treatment. If a prompt response is not achieved, a diagnosis of aHUS should be considered, and treatment with a humanized monoclonal anti-C5 antibody (i.e. eculizumab) should be considered. Recent studies have demonstrated the excellent efficacy of eculizumab for aHUS that is refractory to plasma exchange therapy [24-26]. The reason why normal or moderately reduced plasma ADAMTS13 activity does not rule out TTP is because the test results for ADAMTS13 activity are method-dependent. A discrepant result has been observed between the FRETS-VWF73 assay that uses a fluorescein-labeled VWF fragment derived from A2 domain as a substrate and the collagen-binding assay $[27,28]$ or VWF multimer assay [29]. The cleavage of a peptidyl substrate VWF73 requires a less intact ADAMTS13 protease for full activity [30,31], and vwf73 may be cleaved non-specifically by other leukocyte proteases such as cathepsin G, proteinase 3, elastase, and MMP9 [29] released during the acute episode of TTP, which results in a falsely high level of plasma ADAMTS13 activity.

Sequencing analysis of ADAMTS13 gene may be performed if hereditary TTP is considered to confirm the presence of causative mutations. To date, more than 150 different mutations ( $60 \%$ missense, $\sim 20 \%$ small deletions and insertions, and a small percentage of nonsense and splice site mutations) have been reported in patients with congenital TTP [32-34]. While genotype-phenotype correlation has not been well established, the age of onset of the disease phenotype appears to correlate with the residual plasma ADAMTS13 activity. One study has shown that ADAMTS13 lower levels of activity (less than $3 \%$ ) were associated with earlier age at first TTP episode requiring plasma infusion, more frequent recurrences, and prescription of freshfrozen plasma prophylaxis [35]. Despite of the compound heterozygous mutations in ADAMTS13 gene found in most patients with hereditary TTP, homozygous mutations in these patients were 
reported [36,37]. A majority of ADAMTS13 mutants appear to have folding problems that result in an intracellular retention of the misfolded proteins $[9,36]$.

Upon stimulation or vascular injury, UL-VWF is released from endothelial cells or adhered to sub-endothelial collagen matrix. Platelets are recruited to the sites of activation or injury via interaction with UL-VWF. While cleavage of cell bound UL-VWF does not require shear, fluidic shear stress accelerates the removal or cleavage of ULVWF on endothelium and at the sites of thrombus formation. Binding of platelets and/or coagulation factor VIII to UL-VWF or soluble VWF dramatically enhances its proteolytic cleavage by ADAMTS13 under flow. This regulated process of UL-VWF or large soluble VWF by ADAMTS13 is essential for maintaining normal blood flow. Deficiency of plasma ADAMTS13 activity either resulting from mutations in ADAMTS13 gene or acquired autoantibodies against ADAMTS13 results in accumulation of UL-VWF on endothelium and at the sites of injury, leading to exaggerated platelet aggregation and thrombus formation in small arterioles and capillaries, the characteristic pathological feature of TTP.

Hereditary TTP can be prevented or treated by plasma infusions. Because of a long half-life (2-3 days) for infused plasma ADAMTS13 in patients with hereditary TTP [38], an intermittent infusion of fresh frozen plasma every two to three weeks appears to be sufficient to maintain a plasma levels of ADAMTS13 activity above 5\% that prevents relapses of the disease [39]. The relapses of hereditary TTP are often triggered by infection and/or pregnancy, because there may be inflammatory cytokines or bacterial toxin in circulation that increases the synthesis and release of UL-VWF multimers [40,41]. Further, bacterial toxin has been shown to block the cleavage of ULVWF by ADAMTS13 in vitro [42].

While plasma infusion is the mainstay of treatment for hereditary TTP, recombinant ADAMTS13 is under development for therapy [43] that may minimize the exposure of human plasma and reduce the allergic reactions. AAV8-mediated gene therapy may be curative for hereditary TTP. Animal study has demonstrated a long-term expression of a C-terminal truncated ADAMTS13 variant at therapeutic levels [44]. Other agents such as anti-VWF aptamer [45] or anti-glycoprotein $1 \mathrm{~b}$ (GP1b) nanobody [46], anti-GP1b snake venom (i.e. anfibatide) [47], and a disulfide bond reducing agent such as Nacetylcysteine [48] may be developed as novel therapeutics for hereditary TTP.

In conclusion, the identification and cloning of ADAMTS13 enzyme has provided an invaluable tool for further understanding of the molecular mechanism and developing a novel diagnostic and therapeutic strategy for hereditary TTP.

\section{Acknowledgment}

The work is partially supported by grants from T32HL007971 (to H.H.) and R01HL115187-01A1 (to X.Z.)

\section{References}

1. Moake JL (2002) Thrombotic thrombocytopenic purpura: the systemic clumping "plague". Annu Rev Med 53: 75-88.

2. Bell WR, Braine HG, Ness PM, Kickler TS (1991) Improved survival in thrombotic thrombocytopenic purpura-hemolytic uremic syndrome. Clinical experience in 108 patients. N Engl J Med 325: 398-403.

3. Zheng X, Chung D, Takayama TK, Majerus EM, Sadler JE, et al. (2001) Structure of von Willebrand factor-cleaving protease (ADAMTS13), a metalloprotease involved in thrombotic thrombocytopenic purpura. J Biol Chem 276: 41059-41063.

4. Levy GG, Nichols WC, Lian EC, Foroud T, McClintick JN, et al. (2001) Mutations in a member of the ADAMTS gene family cause thrombotic thrombocytopenic purpura. Nature 413: 488-494.

5. Dong JF, Moake JL, Nolasco L, Bernardo A, Arceneaux W, et al. (2002) ADAMTS-13 rapidly cleaves newly secreted ultralarge von Willebrand factor multimers on the endothelial surface under flowing conditions. Blood 100: 4033-4039.

6. Chauhan AK, Motto DG, Lamb CB, Bergmeier W, Dockal M, et al. (2006) Systemic antithrombotic effects of ADAMTS13. J Exp Med 203: 767-776.

7. Xiao J, Jin SY, Xue J, Sorvillo N, Voorberg J, et al. (2011) Essential domains of a disintegrin and metalloprotease with thrombospondin type 1 repeats-13 metalloprotease required for modulation of arterial thrombosis. Arterioscler Thromb Vasc Biol 31: 2261-2269.

8. Fujimura Y, Matsumoto M, Isonishi A, Yagi H, Kokame K, et al. (2011) Natural history of Upshaw-Schulman syndrome based on ADAMTS13 gene analysis in Japan. J Thromb Haemost 9 Suppl 1: 283-301.

9. Kokame K, Matsumoto M, Soejima K, Yagi H, Ishizashi H, et al. (2002) Mutations and common polymorphisms in ADAMTS13 gene responsible for von Willebrand factor-cleaving protease activity. Proc Natl Acad Sci U S A 99: 11902-11907.

10. Tsai HM, Lian EC (1998) Antibodies to von Willebrand factor-cleaving protease in acute thrombotic thrombocytopenic purpura. N Engl J Med 339: 1585-1594.

11. Zheng XL, Wu HM, Shang D, Falls E, Skipwith CG, et al. (2010) Multiple domains of ADAMTS13 are targeted by autoantibodies against ADAMTS13 in patients with acquired idiopathic thrombotic thrombocytopenic purpura. Haematologica 95: 1555-1562.

12. Zheng XL, Kaufman RM, Goodnough LT, Sadler JE (2004) Effect of plasma exchange on plasma ADAMTS13 metalloprotease activity, inhibitor level, and clinical outcome in patients with idiopathic and nonidiopathic thrombotic thrombocytopenic purpura. Blood 103: 4043-4049.

13. Zheng X, Pallera AM, Goodnough LT, Sadler JE, Blinder MA (2003) Remission of chronic thrombotic thrombocytopenic purpura after treatment with cyclophosphamide and rituximab. Ann Intern Med 138: 105-108.

14. Mise K, Ubara Y, Matsumoto M, Sumida K, Hiramatsu R, et al. (2013) Long term follow up of congenital thrombotic thrombocytopenic purpura (Upshaw-Schulman syndrome) on hemodialysis for 19 years: a case report. BMC Nephrol 14: 156.

15. Fujimura Y, Matsumoto M, Kokame K, Isonishi A, Soejima K, et al. (2009) Pregnancy-induced thrombocytopenia and TTP, and the risk of fetal death, in Upshaw-Schulman syndrome: a series of 15 pregnancies in 9 genotyped patients. Br J Haematol 144: 742-754.

16. Furlan M, Lämmle B (1998) Deficiency of von Willebrand factor-cleaving protease in familial and acquired thrombotic thrombocytopenic purpura. Baillieres Clin Haematol 11: 509-514.

17. George JN (2010) How I treat patients with thrombotic thrombocytopenic purpura: 2010. Blood 116: 4060-4069.

18. Schneppenheim R, Budde U, Oyen F, Angerhaus D, Aumann V, et al. (2003) von Willebrand factor cleaving protease and ADAMTS13 mutations in childhood TTP. Blood 101: 1845-1850.

19. Zheng XL (2010) ADAMTS13 testing: why bother? Blood 115: 1475-1476.

20. Sartz L, Olin AI, Kristoffersson AC, Ståhl AL, Johansson ME, et al. (2012) A novel C3 mutation causing increased formation of the C3 convertase in familial atypical hemolytic uremic syndrome. J Immunol 188: 2030-2037.

21. Tawadrous H, Maga T, Sharma J, Kupferman J, Smith RJ, et al. (2010) A novel mutation in the complement factor B gene (CFB) and atypical hemolytic uremic syndrome. Pediatr Nephrol 25: 947-951.

22. Goicoechea de Jorge E, Harris CL, Esparza-Gordillo J, Carreras L, Arranz EA, et al. (2007) Gain-of-function mutations in complement factor B are associated with atypical hemolytic uremic syndrome. Proc Natl Acad Sci U S A 104: 240-245. 
Citation: Hanby HA, Zheng XL (2014) Current Status in Diagnosis and Treatment of Hereditary Thrombotic Thrombocytopenic Purpura. Hereditary Genet 3: e108. doi:10.4172/2161-1041.1000e108

Page 3 of 3

23. Fremeaux-Bacchi V1, Fakhouri F, Garnier A, Bienaimé F, Dragon-Durey MA, et al. (2013) Genetics and outcome of atypical hemolytic uremic syndrome: a nationwide French series comparing children and adults. Clin J Am Soc Nephrol 8: 554-562.

24. Kavanagh D, Goodship TH (2010) Atypical hemolytic uremic syndrome. Curr Opin Hematol 17: 432-438.

25. Chatelet V, Frémeaux-Bacchi V, Lobbedez T, Ficheux M, Hurault de Ligny B (2009) Safety and long-term efficacy of eculizumab in a renal transplant patient with recurrent atypical hemolytic-uremic syndrome. Am J Transplant 9: 2644-2645.

26. Nürnberger J, Philipp T, Witzke O, Opazo Saez A, Vester U, et al. (2009) Eculizumab for atypical hemolytic-uremic syndrome. N Engl J Med 360: 542-544.

27. Shelat SG, Smith P, Ai J, Zheng XL (2006) Inhibitory autoantibodies against ADAMTS-13 in patients with thrombotic thrombocytopenic purpura bind ADAMTS-13 protease and may accelerate its clearance in vivo. J Thromb Haemost 4: 1707-1717.

28. Mackie I, Langley K, Chitolie A, Liesner R, Scully M, et al. (2013) Discrepancies between ADAMTS13 activity assays in patients with thrombotic microangiopathies. Thromb Haemost 109: 488-496.

29. Kremer Hovinga JA, Vesely SK, Terrell DR, Lämmle B, George JN (2010) Survival and relapse in patients with thrombotic thrombocytopenic purpura. Blood 115: 1500-1511.

30. Shelat SG, Ai J, Zheng XL (2005) Molecular biology of ADAMTS13 and diagnostic utility of ADAMTS13 proteolytic activity and inhibitor assays. Semin Thromb Hemost 31: 659-672.

31. Ai J, Smith P, Wang S, Zhang P, Zheng XL (2005) The proximal carboxylterminal domains of ADAMTS13 determine substrate specificity and are all required for cleavage of von Willebrand factor. J Biol Chem 280: 29428-29434.

32. Raife TJ, Cao W, Atkinson BS, Bedell B, Montgomery RR, et al. (2009) Leukocyte proteases cleave von Willebrand factor at or near the ADAMTS13 cleavage site. Blood 114: 1666-1674.

33. Zheng XL, Sadler JE (2008) Pathogenesis of thrombotic microangiopathies. Annu Rev Pathol 3: 249-277.

34. Lotta LA, Garagiola I, Palla R, Cairo A, Peyvandi F (2010) ADAMTS13 mutations and polymorphisms in congenital thrombotic thrombocytopenic purpura. Hum Mutat 31: 11-19.

35. Lotta LA, Wu HM, Mackie IJ, Noris M, Veyradier A, et al. (2012) Residual plasmatic activity of ADAMTS13 is correlated with phenotype severity in congenital thrombotic thrombocytopenic purpura. Blood 120: 440-448.

36. Meyer SC, Jin SY, Cao WJ, Zheng X, Lammle B, et al. (2008) Characterization of five homozygous ADAMTS13 mutations in hereditary thrombotic thrombocyteopenic purpura-towards a phenotype-genotype correlation? Blood 112: 108
37. Meyer SC, Jeddi R, Meddeb B, Gouider E, Lämmle B, et al. (2008) A first case of congenital TTP on the African continent due to a new homozygous mutation in the catalytic domain of ADAMTS13. Ann Hematol 87: 663-666.

38. Furlan M, Robles R, Morselli B, Sandoz P, Lammle B (1999) Recovery and half-life of von Willebrand factor-cleaving protease after plasma therapy in patients with thrombotic thrombocytopenic purpura. Thrombosis and haemostasis 81: 8-13.

39. Furlan M, Lämmle B (2001) Aetiology and pathogenesis of thrombotic thrombocytopenic purpura and haemolytic uraemic syndrome: the role of von Willebrand factor-cleaving protease. Best Pract Res Clin Haematol 14: 437-454.

40. Bernardo A, Ball C, Nolasco L, Moake JF, Dong JF (2004) Effects of inflammatory cytokines on the release and cleavage of the endothelial cellderived ultralarge von Willebrand factor multimers under flow. Blood 104: 100-106.

41. Huang J, Motto DG, Bundle DR, Sadler JE (2010) Shiga toxin B subunits induce VWF secretion by human endothelial cells and thrombotic microangiopathy in ADAMTS13-deficient mice. Blood 116: 3653-3659.

42. Nolasco LH, Turner NA, Bernardo A, Tao Z, Cleary TG, et al. (2005) Hemolytic uremic syndrome-associated Shiga toxins promote endothelialcell secretion and impair ADAMTS13 cleavage of unusually large von Willebrand factor multimers. Blood 106: 4199-4209.

43. Schiviz A, Wuersch K, Piskernik C, Dietrich B, Hoellriegl W, et al. (2012) A new mouse model mimicking thrombotic thrombocytopenic purpura: correction of symptoms by recombinant human ADAMTS13. Blood 119: 6128-6135.

44. Jin SY, Xiao J, Bao J, Zhou S, Wright JF, et al. (2013) AAV-mediated expression of an ADAMTS13 variant prevents shigatoxin-induced thrombotic thrombocytopenic purpura. Blood 121: 3825-3829, S1-3.

45. Jilma-Stohlawetz P1, Gorczyca ME, Jilma B, Siller-Matula J, Gilbert JC, et al. (2011) Inhibition of von Willebrand factor by ARC1779 in patients with acute thrombotic thrombocytopenic purpura. Thromb Haemost 105: 545-552.

46. Callewaert F, Roodt J, Ulrichts H, Stohr T, van Rensburg WJ, et al. (2012) Evaluation of efficacy and safety of the anti-VWF Nanobody ALX-0681 in a preclinical baboon model of acquired thrombotic thrombocytopenic purpura. Blood 120: 3603-3610.

47. Lei X, Reheman A, Hou Y, Zhou H, Wang Y, et al. (2014) Anfibatide, a novel GPIb complex antagonist, inhibits platelet adhesion and thrombus formation in vitro and in vivo in murine models of thrombosis. Thromb Haemost 111: 279-289.

48. Chen J, Reheman A, Gushiken FC, Nolasco L, Fu X, et al. (2011) Nacetylcysteine reduces the size and activity of von Willebrand factor in human plasma and mice. J Clin Invest 121: 593-603. 